\title{
Experience from Asian centers in a named-patient-use program for afatinib in patients with advanced non-small-cell lung cancer who had progressed following prior therapies, including patients with uncommon EGFR mutations
}

\author{
Gee-Chen Chang ${ }^{1,2,3} \cdot$ David Chi-Leung Lam ${ }^{4} \cdot$ Chun-Ming Tsai $^{5} \cdot$ Yuh-Min Chen $^{6} \cdot$ Jin-Yuan Shih $^{7} \cdot$ Shyam Aggarwal $^{8}$. \\ Shuhang Wang ${ }^{9}$. Sang-We Kim ${ }^{10}$ - Young-Chul Kim ${ }^{11} \cdot$ Ibrahim Wahid $^{12} \cdot$ Rubi Li $^{13} \cdot$ Darren Wan-Teck Lim ${ }^{14}$. \\ Virote Sriuranpong ${ }^{15} \cdot$ Raymond Tsz-Tong Chan $^{16} \cdot$ Robert M. Lorence $^{17} \cdot$ Philippe Carriere $^{17} \cdot$ Christina Raabe $^{18}$. \\ Agnieszka Cseh ${ }^{19} \cdot$ Keunchil Park ${ }^{20}$
}

Received: 5 June 2020 / Accepted: 1 January 2021 / Published online: 30 March 2021

(c) The Author(s) 2021

\begin{abstract}
Background This study evaluated outcomes among patients with advanced/metastatic non-small-cell lung cancer (NSCLC) treated at Asian centers participating in the global named-patient-use (NPU) program for afatinib.

Methods Patients had progressed after initial benefit with erlotinib or gefitinib, and/or had an EGFR or HER2 mutation, had no other treatment options, and were ineligible for afatinib trials. The recommended starting dose of afatinib was $50 \mathrm{mg} / \mathrm{day}$. Dose modifications were allowed, and afatinib was continued as long as deemed beneficial. Response and survival information was provided voluntarily. Safety reporting was mandatory.

Results 2242 patients ( $26 \%$ aged $\geq 70$ years, $96 \%$ with adenocarcinoma) received afatinib at centers in 10 Asian countries. Most were heavily pre-treated, including prior treatment with erlotinib or gefitinib. Of 1281 patients tested, 1240 had EGFR mutations (common: 1034/1101; uncommon: 117/1101). There were no new safety signals, the most common adverse events being rash and diarrhea. Objective response rate (ORR) was $24 \%$ overall ( $n=431$ with data available), $27 \%$ for patients with common EGFR mutations $(n=230)$ and $28 \%$ for those with uncommon mutations $(n=32)$; median time to treatment failure (TTF) in these groups was 7.6 months $(n=1550), 6.4$ months $(n=692)$ and 8.4 months $(n=83)$, respectively. In patients with EGFR exon 20 insertions $(n=23)$ and HER2 mutations $(n=12)$, median TTF exceeded 12 months.

Conclusions Patient outcomes in this study were similar to those reported in the analysis of the global NPU. Afatinib achieved clinical benefits in patients with refractory NSCLC. ORR and TTF were similar between patients with tumors harboring uncommon and common EGFR mutations.
\end{abstract}

Keywords Afatinib $\cdot H E R 2$ mutations $\cdot$ Lung cancer $\cdot$ Named patient use $\cdot$ NSCLC $\cdot$ Uncommon EGFR mutations

\section{Introduction}

Afatinib is an irreversible inhibitor of the ErbB receptor family (EGFR [epidermal growth factor receptor]/ErbB1; HER2 [human epidermal growth factor receptor 2]/ErbB2; and HER4/ErbB4). In contrast to the first-generation EGFR tyrosine kinase inhibitors (TKIs) erlotinib and gefitinib, which bind reversibly to the ErbB1 receptor, afatinib

Gee-Chen Chang

geechen@gmail.com

Extended author information available on the last page of the article covalently binds to all ErbB family receptors, blocking signaling and causing sustained inhibition of mitogenic activity $[1,2]$. Afatinib is approved in the European Union, USA, Canada, Switzerland, Australia, and several Asian, Latin American, and Middle Eastern countries as an oral, oncedaily tablet for patients with non-small-cell lung cancer (NSCLC) and activating EGFR mutations. In addition to the common mutations, exon 19 deletions (del19) and L858R substitutions, there is evidence that afatinib is active against some uncommon EGFR mutations, including L861Q, G719X, and S768I [3]. 
A global named-patient-use (NPU) program for afatinib was initiated in Germany and Australia in May 2010, for patients with advanced or metastatic NSCLC who had progressed after clinical benefit during previous treatment with erlotinib or gefitinib and/or had an activating EGFR/HER2 mutation, had exhausted all other treatments and were ineligible for an afatinib trial. The main objective of the program was to provide compassionate access to treatment for patients with no other established therapeutic options. The program continued until January 2016, by which time a total of 5636 patients had been treated in 49 countries on six continents. In an analysis of treatment outcomes in 3966 patients from 41 countries (excluding Taiwan), the median time to treatment failure (TTF) was 4.4 months and the objective response rate (ORR) was $23 \%$ [4]. Outcomes of patients treated in centers in specific countries [5-8], and with HER2 mutations [9] have also been described.

Here we present an analysis of treatment outcomes in patients who were treated at centers in 10 Asian countries. The large size of the NPU program made it possible to evaluate treatment outcomes in patients with both common and uncommon $E G F R$ mutations. Understanding the influence of $E G F R$ mutations is particularly important for patients in Asian countries, as EGFR mutations are prevalent among patients from this region [10].

\section{Materials and methods}

The design of the NPU has been reported previously [4]. Key details are summarized below.

\section{Patients}

Patients were eligible if they had advanced/metastatic NSCLC, had progressed after initially achieving clinical benefit (complete response [CR], partial response [PR], or stable disease [SD] lasting at least 6 months) during treatment with erlotinib or gefitinib and/or had an activating EGFR mutation or a HER2 mutation, had exhausted other treatment options and were ineligible to participate in an afatinib trial. Previous TKI therapy was not mandatory for all patients with confirmed mutations. Chemotherapy-naïve patients were eligible for inclusion if they were unfit to receive chemotherapy and were deemed ineligible to participate in an actively recruiting afatinib trial. The NPU program procedures (including enrollment criteria and treatment details) were adapted locally and approved in each region according to local regulations. The current analysis was conducted using data collected for patients treated at centers in Asian countries only.

\section{Afatinib dose}

The recommended starting dose of afatinib was $50 \mathrm{mg} /$ day, as used in the phase III LUX-Lung 1 study of afatinib following failure of prior erlotinib/gefitinib [11]. Lower starting doses ( 40 or $30 \mathrm{mg}$ /day) were allowed at the discretion of the treating physician. Tolerability-guided dose modifications were also allowed, using $10-\mathrm{mg}$ steps to a maximum of $50 \mathrm{mg} /$ day and a minimum of $30 \mathrm{mg} /$ day. Afatinib was continued as long as deemed beneficial by the treating physician.

Enrollment into the NPU program was terminated within each country once afatinib became commercially available locally; enrollment had ceased worldwide by January 2016 . In some countries, patients were switched to commercially available afatinib provided by Boehringer Ingelheim; in others, patients continued to receive afatinib via the NPU program. In both cases, afatinib was continued as long as treatment was deemed beneficial by the treating physician.

\section{Outcome measures}

TTF was defined as the time from the date of initiation of afatinib to the date of discontinuation, switch to another drug, death, or the last available data, whichever occurred first. The ORR was defined as the proportion of patients with a recorded response outcome (CR, PR, SD, progressive disease [PD], or mixed response) who achieved a CR or PR. The disease control rate (DCR) was defined as a proportion of patients with response information available who achieved a CR, PR, or SD. There was no independent radiologic verification of responses, $\mathrm{SD}$ or $\mathrm{PD}$.

Physicians were required to report safety-related information including all adverse events (AEs) leading to discontinuation of afatinib or deemed to be related to afatinib by the treating physician, and all serious AEs.

\section{Data capture and analysis}

Data collected during the program were provided voluntarily by the participating physicians and only safety reporting was mandatory.

No site monitoring, site audits, data cleaning, or structured data collection was conducted, except for the use of standard serious AE forms and reporting. Data were analyzed using SAS ${ }^{\circledR}$ software (Version 9.4, SAS Institute, Inc., NC, USA). The cut-off date for data analysis was January 18, 2016.

Baseline demographics and outcomes during treatment with afatinib were analyzed. Subgroup analyses were also 
conducted, including analyses of groups defined by the presence or absence of common and uncommon EGFR mutations, specific EGFR mutations, and HER2 mutations.

\section{Ethics}

All procedures were approved by the responsible ethics committees and the required country-specific and regional regulatory authorities were informed about the program.

The datasets generated and analyzed during the NPU program are available from the corresponding author on reasonable request.

\section{Results}

\section{Patient characteristics and treatment}

As of the cut-off date, 2242 patients with NSCLC had received afatinib at treatment centers across 10 Asian countries (Table 1); $26 \%$ were aged $\geq 70$ years. Of the 1924 patients with known tumor histology, $96 \%$ had adenocarcinoma. Most patients were heavily pre-treated; of the 2242 patients treated with afatinib, 2223 had received at least one line of previous therapy and 2202 had been treated with erlotinib and/or gefitinib. Sixty-two percent had previously received at least two lines of chemotherapy and 65\% had received at least three lines of systemic therapy (Table 2). Nineteen patients who were ineligible for chemotherapy received first-line afatinib at the request of the treating physicians on the basis that they considered it of potential benefit.

Mutation status was reported for 1281/2242 patients (57\%), $97 \%$ of whom were EGFR mutation-positive (Table 3). Among patients with a specified EGFR mutation, 94\% had a common EGFR mutation and $11 \%$ had an uncommon EGFR mutation, including 47 patients with T790M, 45 patients with G719X, L861Q or S768I, and 35 patients with EGFR ex20ins (Table 3).

Twelve patients were $H E R 2$ mutation-positive, with no concurrent EGFR mutations. Seven had a specified HER2 mutation, all being p.A775_G776insYVMA insertions at nucleotide 2325 (Table 3).

\section{Response to therapy, overall and according to mutation status}

Information on response to afatinib was provided for 431 patients (19\%), 78\% of whom (335/431) had PR or SD; the ORR was $24 \%$ and the DCR was $78 \%$ (Table 4). Among patients with available information on both response and mutation status, ORR was $28 \%$ in patients with $E G F R$ mutations $(n=267), 27 \%$ in those with common $E G F R$ mutations $(n=230)$, and $28 \%$ in those with uncommon
Table 1 Baseline demographic and clinical characteristics

\begin{tabular}{|c|c|}
\hline Characteristic, $n(\%)$ & $N=2242$ \\
\hline \multicolumn{2}{|l|}{ Country } \\
\hline \multicolumn{2}{|l|}{ Eastern Asia } \\
\hline Taiwan $^{\mathrm{a}}$ & $840(37.5)$ \\
\hline Republic of Korea & $377(16.8)$ \\
\hline Hong Kong & $302(13.5)$ \\
\hline Philippines & $154(6.9)$ \\
\hline Singapore & $145(6.5)$ \\
\hline Thailand & $108(4.8)$ \\
\hline Malaysia & $96(4.3)$ \\
\hline China & $48(2.1)$ \\
\hline Indonesia & $18(0.8)$ \\
\hline \multicolumn{2}{|l|}{ Non-Eastern Asia } \\
\hline India & $154(6.9)$ \\
\hline Gender $^{b}$ & $N=2220$ \\
\hline Male & $896(40.4)$ \\
\hline Female & $1324(59.6)$ \\
\hline Age $^{\mathrm{b}}$, years & $N=2192$ \\
\hline Median & 61 \\
\hline $25^{\text {th }}$ percentile & 53 \\
\hline $75^{\text {th }}$ percentile & 70 \\
\hline $70-80, n(\%)$ & $444(20.3)$ \\
\hline$\geq 80, n(\%)$ & $120(5.5)$ \\
\hline Histology $y^{b}$ & $N=1924$ \\
\hline Adenocarcinoma & $1853(96.3)$ \\
\hline Squamous cell carcinoma & $21(1.1)$ \\
\hline Large cell carcinoma & $3(0.2)$ \\
\hline Other & $47(2.4)$ \\
\hline Starting dose of afatinib ${ }^{b}, \mathrm{mg} /$ day & $N=1333$ \\
\hline 50 & $609(45.7)$ \\
\hline 40 & $631(47.3)$ \\
\hline 30 & $93(7.0)$ \\
\hline
\end{tabular}

Data cut: January 18, 2016

$N P U$ named-patient-use

${ }^{\text {a}}$ Patients from Taiwan were omitted from a previous report on the global NPU program (Cappuzzo et al. 2018) [4] due to a misunderstanding

${ }^{\mathrm{b}}$ Patients whose physicians provided relevant information

EGFR mutations ( $n=32)$. In patients with G719X, L861Q, or S768I $(n=7)$, the ORR was $43 \%$ (Table 4$)$. For patients with a specified HER 2 mutation, 4/7 had response information available; all four had disease control (PR or SD) and one of the four had a PR (Table 4). In patients with a $<6$-month interval between discontinuing previous EGFR TKI treatment and initiating afatinib $(n=586)$, the ORR was $23.5 \%$ and the DCR was $78.2 \%$. In those patients with a $<12$ month interval $(\mathrm{n}=986)$, the ORR and DCR were 25.5 and $78.2 \%$, respectively. 
Table 2 Previous therapies

\begin{tabular}{ll}
\hline Therapy $^{\text {a }}$ & $N=2242$ \\
\hline No previous treatment reported, $n(\%)$ & $19(0.8)$ \\
Any previous treatment, $n(\%)$ & $2223(99.2)$ \\
Previous lines of chemotherapy, median (IQR) & $2(1-3)$ \\
Previous lines of chemotherapy (\%) & \\
$\geq 3$ & 32 \\
$\geq 2$ & 62 \\
1 & 23 \\
0 & 15 \\
Previous lines of systemic therapy, median (IQR) & $3(2-4)$ \\
Previous lines of systemic therapy (\%) & \\
$\geq 4$ & 37 \\
$\geq 3$ & 65 \\
2 & 21 \\
1 & 14 \\
0 & 0 \\
Previous TKI use & \\
Any TKI ${ }^{\mathrm{b}} n$ (\%) & $2202 / 2223(99.1)$ \\
Erlotinib and/or gefitinib & $2202(99.1)$ \\
Erlotinib only & $866 / 2202(39.3)$ \\
Gefitinib only & $927 / 2202(42.1)$ \\
Erlotinib and gefitinib & $409 / 2202(18.6)$ \\
\hline
\end{tabular}

$I Q R$ interquartile range, $T K I$ tyrosine kinase inhibitor

${ }^{a}$ Patients whose physicians provided information on previous therapies

${ }^{\mathrm{b}}$ Erlotinib, gefitinib, lapatinib, trastuzumab, or afatinib

\section{TTF, overall and according to mutation status and previous use of TKls}

Among the 1550 patients (69\%) for whom TTF data were available, median TTF was 7.6 months (Table 5). Among those for whom information on both TTF and mutation status was available, median TTF was 7.2 months for patients with $E G F R$ mutations $(n=834), 6.4$ months for those with common $E G F R$ mutations $(n=692)$ and 8.4 months for those with uncommon EGFR mutations $(n=83)$. In patients with G719X, L861Q, or S768I mutations $(n=28)$, median TTF was 7.8 months, but in those with EGFR ex20ins $(n=23)$ and HER2 mutations $(n=12)$, median TTF exceeded 12 months.

Median TTF for patients who had previously received erlotinib or gefitinib was 8.7 months, and 8.2 months for those who had previously responded (CR/PR) to erlotinib (Table 5). In patients with $<6-/<12$-month intervals between the discontinuation of prior EGFR TKI treatment and initiating afatinib, median TTF was 8.4 and 7.6 months, respectively.
Table 3 Tumor EGFR and HER2 mutation status

\begin{tabular}{ll}
\hline Mutation status, $n(\%)$ & \\
\hline$E G F R$ & $N=1281^{\mathrm{a}}$ \\
Mutation-positive & $1240 / 1281\left(96.8^{\mathrm{b}}\right)$ \\
Site of mutation specified & $1101 / 1240\left(88.8^{\mathrm{c}}\right)$ \\
Common EGFR mutations (del19 or L858R) & $1034 / 1101\left(93.9^{\mathrm{d}}\right)$ \\
Uncommon EGFR mutations (any) & $117 / 1101\left(10.6^{\mathrm{d}}\right)$ \\
T790M & $47 / 117\left(40.2^{\mathrm{e}}\right)$ \\
G719X, L861Q, S768I & $45 / 117\left(38.5^{\mathrm{e}}\right)$ \\
ex20ins & $35 / 117\left(29.9^{\mathrm{e}}\right)$ \\
Wild-type & $41 / 1281\left(3.2^{\mathrm{b}}\right)$ \\
Not reported & 961 \\
HER2 & \\
Total ${ }^{\mathrm{a}}$ HER2 mutation-positive & $12\left(0.5^{\mathrm{b}}\right)$ \\
Also EGFR mutation-positive & $0 / 12\left(0^{\mathrm{b}}\right)$ \\
HER2 mutation specified & $7 / 12\left(58^{\mathrm{f}}\right)$ \\
p.A775_G776insYVMA HER2 & $7 / 7\left(100^{\mathrm{g}}\right)$ \\
\hline
\end{tabular}

del19 exon 19 deletions, EGFR epidermal growth factor receptor, HER2 human epidermal growth factor receptor 2, L858R Leu858Arg point mutations in exon 21

${ }^{\text {a }}$ Patients whose physician volunteered information on the presence or absence of the specified mutations

The denominators used to calculate the percentage data were:

${ }^{\mathrm{b}}$ Total number of patients with mutation status available

${ }^{\mathrm{c}}$ Number of $E G F R$ mutation-positive patients

${ }^{\mathrm{d}}$ Number of patients with specified $E G F R$ mutations

${ }^{\mathrm{e}}$ Number of patients with specified uncommon EGFR mutations

${ }^{\mathrm{f}}$ Number of HER2 mutation-positive patients

${ }^{\mathrm{g}}$ Number of patients with specified HER2 mutations

\section{Adverse events}

The most frequently reported AEs were rash and diarrhea (Table 6).

\section{Discussion}

This analysis of patients from Asian countries involved in the afatinib NPU program revealed clinically meaningful ORRs and TTF in this heavily pretreated and resistant/ refractory advanced NSCLC patient population. Ninetyseven percent of patients with information on EGFR mutation status were EGFR mutation-positive, whereas $93 \%$ of the global NPU population were EGFR mutation-positive (2407/2595 patients, excluding patients from Taiwan) [4].

The findings of this study were generally similar to those of an analysis of the global NPU population [4]. This is an important finding as, without evidence, it cannot be assumed that patients from Asia respond similarly to those from other regions. However, median TTF for EGFR mutation-positive 
Table 4 Response to afatinib

\begin{tabular}{|c|c|}
\hline \multicolumn{2}{|l|}{ Reported response, $n(\%)$} \\
\hline Objective response rate (ORR) & $105 / 431(24.4)$ \\
\hline Partial response & $105(24.4)^{\mathrm{a}}$ \\
\hline Complete response & 0 \\
\hline Mixed response & 0 \\
\hline Stable disease & $230(53.4)^{\mathrm{a}}$ \\
\hline Progressive disease & $96(22.3)^{\mathrm{a}}$ \\
\hline Disease control rate & $335(77.7)^{\mathrm{a}}$ \\
\hline \multicolumn{2}{|l|}{ ORR by mutation status } \\
\hline$E G F R$ mutation-positive ${ }^{\mathrm{b}}$ & $74 / 267(27.7)$ \\
\hline Common EGFR mutations (del19 or L858R) & $63 / 230(27.4)$ \\
\hline Uncommon EGFR mutations (any) & $9 / 32(28.1)$ \\
\hline T790M & $5 / 20(25.0)$ \\
\hline G719X, L861Q, S768I & $3 / 7(42.9)$ \\
\hline ex20ins & $1 / 5(20.0)$ \\
\hline HER2 mutation-positive & $1 / 7(14.2)$ \\
\hline p.A775_G776insYVMA & $1 / 4(25.0)$ \\
\hline \multicolumn{2}{|l|}{ ORR by prior TKI use } \\
\hline In patients with $\geq 2$ years' previous use of erlotinib or gefitinib & $8 / 84(9.5)$ \\
\hline In patients with $\mathrm{PR} / \mathrm{CR}$ during previous use of erlotinib & $30 / 124(24.2)$ \\
\hline \multicolumn{2}{|c|}{$\begin{array}{l}C R \text { complete response, del19 exon } 19 \text { deletions, } E G F R \text { epidermal growth factor receptor, ex20ins exon } 20 \\
\text { insertions, } H E R 2 \text { human epidermal growth factor receptor } 2, L 858 R \text { Leu } 858 \text { Arg point mutations in exon } \\
21, M R \text { mixed response, } O R R \text { objective response rate, } P R \text { partial response, } T K I \text { tyrosine kinase inhibitor }\end{array}$} \\
\hline \multicolumn{2}{|c|}{$\begin{array}{l}\text { a Percentage response is based on the total number of patients with information available on the response } \\
\text { to afatinib, as well as documented evidence of having received afatinib through the reported start date } \\
(n=431)\end{array}$} \\
\hline
\end{tabular}

patients was 7.2 months for the Asian centers, compared with 4.3 months for the global NPU program, while the ORRs were $28 \%$ and $25 \%$, respectively. The disparity in median TTF may have been influenced by differences between regions in the rates of reporting of key end dates, such as end of treatment and date of death. The median TTF for patients in this analysis of data from Asian centers may also have been influenced by the particularly prolonged TTF of patients in Taiwan 14.2 months $(n=273)$ [12]. When the NPU program began, investigators/clinicians in Taiwan had already gained experience in the use of afatinib, through their involvement in phase I and II trials. As a result, they may have been able to optimize their use of afatinib, potentially through more successful management of side effects, thereby allowing patients to remain on treatment for longer and to achieve greater clinical benefit. In contrast, in many other countries, physicians' first experience with afatinib was within the NPU.

The clinical benefits of afatinib appeared to be similar between patients with NSCLC tumors harboring common or uncommon EGFR mutations. The median TTF in the subgroup with uncommon EGFR mutations was 8.4 months, versus 6.4 months in the subgroup with common $E G F R$ mutations; ORR was $28 \%$ and $27 \%$, respectively. In the global NPU program, TTF was 4.3 months in both subgroups [4], while ORR was $26 \%$ and $25 \%$, respectively [4].

In the current analysis, among the 28 patients with G719X, L861Q, or S768I mutations, median TTF was 7.8 months, compared with 4.7 months for patients with these mutations in the global NPU population $(n=77$; [4]). The ORR in the current analysis was $43 \%$ (3/7 patients), compared with $30 \%$ (8/27 patients) in the global NPU analysis [4]. The difference in median TTF between patients with G719X, L861Q, or S768I mutations in the Asian subgroup and the global NPU program may have been particularly influenced by the median of 21.1 months among patients from Taiwan [12], who were not included in the global NPU analysis [4]. However, the prolonged outcomes reported here for patients with G719X, L861Q, or S768I mutations are in agreement with data from the LUX-Lung 2, 3, and 6 studies; for patients with G719X, L861Q or S768I, ORR ranged from 56 to $100 \%$, median PFS 8-15 months, and median OS was 17 months-not estimated. The authors concluded that afatinib has activity against NSCLC tumors harboring these types of uncommon EGFR mutations [3].

Compared with patients with other EGFR mutations, patients with $E G F R$ ex20ins have been reported to respond relatively infrequently to first-generation TKIs [13-15] 
Table 5 Time to treatment failure

\begin{tabular}{|c|c|c|}
\hline & $n$ & $\begin{array}{l}\text { Median TTF } \\
\text { months (IQR) }\end{array}$ \\
\hline Overall $^{\mathrm{a}}, N$ & 1550 & $7.6(2.6-24.3)$ \\
\hline \multicolumn{3}{|l|}{ Mutation status } \\
\hline$E G F R$ mutation-positive & 834 & $7.2(2.5-22.6)$ \\
\hline Specified $E G F R$ mutation (common or uncommon) & 740 & $6.5(2.3-22.4)$ \\
\hline Common EGFR mutations (del19 or L858R) & 692 & $6.4(2.3-22.4)$ \\
\hline Uncommon EGFR mutations (any) & 83 & $8.4(1.9-22.4)$ \\
\hline T790M & 35 & $5.9(1.9-10.8)$ \\
\hline G719X, L861Q, S768I & 28 & $7.8(0.8-25.4)$ \\
\hline ex20ins & 23 & $18.9(8.5-27.4)$ \\
\hline HER2 mutation-positive & 12 & $12.2(2.6-25.2)$ \\
\hline p.A775_G776insYVMA & 7 & $12.4(4.0-15.8)$ \\
\hline \multicolumn{3}{|l|}{ Prior TKI use } \\
\hline Any previous use of erlotinib or gefitinib & 922 & $8.7(2.8-25.2)$ \\
\hline$\geq 2$ years previous use of erlotinib or gefitinib & 338 & $10.2(3.5-26.5)$ \\
\hline $\begin{array}{l}\text { Any reported response }(\mathrm{PR}, \mathrm{CR}, \mathrm{MR}, \mathrm{SD}, \mathrm{PD}) \text { during previous use } \\
\text { of erlotinib }\end{array}$ & 865 & $8.7(2.8-24.7)$ \\
\hline $\mathrm{PR} / \mathrm{CR}$ reported during previous use of erlotinib & 383 & $8.2(2.6-23.5)$ \\
\hline
\end{tabular}

$C R$, complete response; del19, exon 19 deletion; EGFR, epidermal growth factor receptor; ex20ins, exon 20 insertions; $I Q R$, interquartile range; $L 858 R$ Leu858Arg point mutations in exon $21, M R$, mixed response; $P D$, progressive disease; $P R$, partial response; $S D$, stable disease, $T K I$, tyrosine kinase inhibitor; $T T F$, time to treatment failure

${ }^{\text {a }}$ Patients whose physicians provided information on TTF, and documented evidence of having received afatinib through the reported start date
Table 6 Most frequently reported $\mathrm{AEs}^{\mathrm{a}}$ of any grade $(\geq 1 \%$ of patients receiving afatinib)

\begin{tabular}{ll}
\hline $\mathrm{AE}$ & $\mathrm{N}$ \\
\hline Rash/pruritus/dry skin/dermatitis acneiform/acne & 536 \\
Diarrhea & 515 \\
Stomatitis/mucosal inflammation & 326 \\
Paronychia & 203 \\
Decreased appetite & 147 \\
Nausea/vomiting & 123 \\
Fatigue/asthenia & 78 \\
Pneumonia & 69 \\
Pleural effusion & 37 \\
Cough & 36 \\
Pyrexia & 35 \\
\hline
\end{tabular}

The data shown are AE counts, not the numbers of patients with each AE. An individual patient could have several episodes or counts of a particular AE

The data are not shown as percentages because of the risk that this could be misunderstood as representing the percentage of patients with each $\mathrm{AE}$, as a proportion of the total number of patients

$A E$ adverse event

${ }^{a}$ Excludes malignant neoplasm progression and death and have poorer survival outcomes than those with common EGFR mutations [16]. One review of 84 patients with ex20ins (based on eight small series of between 2 and 25 patients) treated with gefitinib or erlotinib found a response rate of $11 \%$ [17]. In another study, median TTF for 8 patients with EGFR ex20ins taking erlotinib for advanced disease was 2.4 months, compared with 5.9 months for 17 patients taking combination chemotherapy [16]. In the LUX-Lung 2, 3 , and 6 trials, responses to afatinib were least common in patients with ex20ins, with two of 23 patients (8.7\%) having an objective response [3]. Afatinib did not confer clinical benefit in these patients. Median PFS was 2.7 months $(n=23)$, which was similar to the PFS of 2.9 months in 14 patients with de-novo T790M resistance mutations [3]. Based on the evidence to date, NSCLC patients harboring EGFR ex20ins have been described as a unique subset, for whom there are no effective approved targeted therapies [15].

In terms of response to treatment, our findings for patients with ex20ins are similar to previous reports. In this study, 1/5 patients with ex20ins (20\%) exhibited PR with afatinib, with $7 / 20$ patients $(35 \%)$ in the analysis of the global NPU program [4]. The median TTF for 23 patients with EGFR ex20ins in this study, however, was 18.9 months, longer than for any other subgroup in this analysis, and much longer than the median of 3.6 months for patients with ex20ins in 
the global NPU program $(n=57)$ [4]. This disparity may be explained, in part, by the presence of clinical and biochemical heterogeneity between different types of $E G F R$ ex20ins, which actually represent a broad subtype of $E G F R$ mutations. Kosaka et al. [15] identified at least 19 different types of ex20ins [15], which differed markedly in their susceptibility to afatinib in vitro. While most ex20ins are resistant to EGFR inhibitors, one appears to confer sensitivity to erlotinib (A763_Y764insFQEA) [18, 19]. There is also evidence that the nature of the ex20ins can influence sensitivity to afatinib. A patient in the NPU program with an EGFR ex20ins (A767_S768insSVA tandem duplication) was maintained at minimal PD for 54 months and received afatinib for 36 months [20]; this raises the possibility that some patients with $E G F R$ ex20ins may obtain benefit from afatinib in this setting. Recently, Liu et al. [21] identified ex20ins in $2 \%$ of Chinese patients with lung cancer $(171 / 7,520)$; detailed survival information during afatinib monotherapy was available for 19 patients. Those harboring G778_P780dup (G778) had longer PFS (median 10 vs. 3.3 months, $p=0.32$ ) and OS (median 19.7 vs. 7 months, $p=0.16$ ) than those with other ex20ins [21]. A limitation of the current analysis is that ex20ins type was not identified for most patients. This may be important for the correct interpretation of therapeutic outcomes in patients with ex20ins and should be considered in future studies.

All 12 patients who were $H E R 2$ mutation-positive were treated at centers in Taiwan, and all specified HER2 mutations were in exon 20. Most HER2 mutations are in exon 20 , occurring in $2-4 \%$ of patients with NSCLC [22-25]. In the current analysis, median TTF in this subgroup was 12.2 months, and 12.4 months in the 7 patients with the p.A775_G776insYVMA HER2 mutation. For the 28 HER2 mutation-positive patients in the global NPU, the median TTF was 2.9 months, but eight of the 28 patients (29\%) had TTF $>1$ year. The most frequent HER2 mutation was p.A775_G776insYVMA (insertion at nucleotide 2325), which was identified in 10 of the 12 patients with specified HER2 mutations (83\%). The median TTF for these patients was 9.6 months [9].

During the NPU program, the third-generation EGFR TKI osimertinib was approved for patients with $E G F R$ T790M-mutation-positive NSCLC, following acquired resistance to EGFR TKIs. In a phase II study, the ORR of osimertinib in pretreated T790M-positive NSCLC patients was $62 \%$ [26], higher than reported here (25\%). Osimertinib has also been reported to achieve a high response rate in patients with the uncommon L861Q and G719A/C/D/S/X EGFR mutations [27]. The effects of osimertinib treatment in patients with other uncommon $E G F R$ mutations have not been reported but, given its specificity for EGFR/ErbB1, unlike afatinib, osimertinib would not be expected to confer benefits in patients with $H E R 2$ mutations.
The safety data observed across the Asian centers were consistent with those reported from non-Asian centers in the NPU program $[4,7,8]$ and with the known safety profile of afatinib. Several of the more frequently reported events were not considered to be side effects of afatinib but were symptoms or consequences of advanced-stage lung cancer or disease progression (e.g. fatigue/asthenia, pneumonia, pleural effusion, and cough).

The current analysis has some limitations. The data generated by the NPU program were derived from patients treated in accordance with local clinical practices, but data collection relied on voluntary reporting of patient information by the investigators. Consequently, the proportions of patients with data available on tumor histology, EGFR mutation type, response and TTF were relatively low. Also, physicians may have been less spontaneous in providing information on response if their patients did not show a significant therapeutic response; this could have led to under-reporting of patients who did worse, and overestimation of ORR and TTF. Centralized radiographic confirmation of tumor response/SD was not available. The data may also have been influenced by failures to report certain end dates, such as end of treatment and date of death. Additionally, AEs may have been under-reported in this real-world setting compared with the rates of reporting generally seen in clinical trials. Finally, information on EGFR mutation status was available for $57 \%$ of the patients, but the validation of the results by a central laboratory was not available. No information was available on the timing of the mutation analysis, particularly in relation to the timing of first-generation TKI therapy. Nevertheless, this afatinib NPU program provided practical data on the safety and efficacy of afatinib in the setting of local clinical practices in diverse Asian countries, while facilitating compassionate use of afatinib in a large group of NSCLC patients who had exhausted all other treatment options.

\section{Conclusions}

The findings of the current analysis of data from Asian centers and those of the global NPU [4] were generally similar. Afatinib achieved clinical benefits in patients with refractory NSCLC, both with common and uncommon EGFR mutations. In patients with tumors harboring uncommon $E G F R$ mutations, estimates of ORR and TTF were similar, if not superior, to those in patients with common EGFR mutations. The variation in the efficacy of afatinib treatment in NSCLC harboring different uncommon mutations remains an important area for future research.

Acknowledgements The NPU program was funded by Boehringer Ingelheim Inc. Medical writing support was funded by Boehringer 
Ingelheim Inc., and was provided by Michael Simpson, $\mathrm{PhD}$, CMPP, of GeoMed, an Ashfield company, part of UDG Healthcare plc.

Data sharing statement To ensure independent interpretation of clinical study results, Boehringer Ingelheim grants all external authors access to all relevant material, including participant-level clinical study data, and relevant material as needed by them to fulfill their role and obligations as authors under the ICMJE criteria. Furthermore, clinical study documents (e.g. study report, study protocol, statistical analysis plan) and participant clinical study data are available to be shared after the publication of the primary manuscript in a peer-reviewed journal and if regulatory activities are complete and other criteria met per the BI Policy on Transparency and Publication of Clinical Study Data: https://trials.boehringer-ingelheim.com/transparency_policy.html. Prior to providing access, documents will be examined, and, if necessary, redacted and the data will be de-identified, to protect the personal data of study participants and personnel, and to respect the boundaries of the informed consent of the study participants. Clinical Study Reports and Related Clinical Documents can be requested via this link: https://trials.boehringer-ingelheim.com/trial_results/clinical_submi ssion_documents.html. All such requests will be governed by a Document Sharing Agreement. Bonafide, qualified scientific and medical researchers may request access to de-identified, analyzable participant clinical study data with corresponding documentation describing the structure and content of the datasets. Upon approval, and governed by a Data Sharing Agreement, data are shared in a secured data-access system for a limited period of 1 year, which may be extended upon request. Researchers should use https://trials.boehringer-ingelheim.com to request access to study data.

\section{Compliance with ethical standards}

Conflict of interest DC-LL received research funding from Astrazeneca, Boehringer Ingelheim, and Novartis for research projects on respiratory diseases in 2019. J-YS received honoraria from AstraZeneca, Roche, Boehringer Ingelheim, Eli Lilly, Pfizer, Novartis, MSD, Ono Pharmaceutical, Chugai Pharmaceutical; and received funding for other items (e.g. trips, travel or gifts) from Roche, MSD, Chugai Pharmaceutical, Bristol-Myers Squibb and Pfizer. SA reports advisory board meeting relationship with Boehringer Ingelheim, Dr Reddy's Laboratories and Intas Biopharmaceuticals. Y-CK received honoraria and research funding from Boehringer Ingelheim, AstraZeneca, and Roche. RL received honoraria from Boehringer Ingelheim. DW-TL received honoraria from Bristol-Myer Squibb, Merck, Taiho, Pfizer, and Roche; and received research funding from Bristol-Myer Squibb. VS reports advisory board meeting relationship with MSD, Novartis, Pfizer, Roche, Eisai, and Amgen; received speaker fees from AstraZeneca, Novartis, Roche, Pfizer, Sanofi, Eisai, Boehringer Ingelheim, Taiho, MSD, BMS, and Amgen; and received clinical research funding through institution from AstraZeneca, Novartis, Roche, Pfizer and MSD. RML reports former employment with and current consultancy for Boehringer Ingelheim Pharmaceuticals, Inc. PC reports employment with Boehringer Ingelheim Pharmaceuticals, Inc. CR reports employment with Boehringer Ingelheim International $\mathrm{GmbH}$. AC reports employment with Boehringer Ingelheim RCV GmbH \& Co KG. $\mathrm{KP}$ reports employment with/leadership position for/advisory role for: AbbVie, AMGEN, Astellas Pharma, AstraZeneca, BluePrint, BMS, Boehringer Ingelheim, Daiichi Sankyo, Eli Lilly, GSK, Hanmi, Incyte, Kyowa Hakko Kirin, LOXO, Merck KGaA, MSD, Novartis, ONO Pharmaceutical and Roche; and received research funding from AstraZeneca and MSD. G-CC, C-MT, Y-MC, SW, IW, S-WK, and RT-TC report no conflicts of interest.
Open Access This article is licensed under a Creative Commons Attribution 4.0 International License, which permits use, sharing, adaptation, distribution and reproduction in any medium or format, as long as you give appropriate credit to the original author(s) and the source, provide a link to the Creative Commons licence, and indicate if changes were made. The images or other third party material in this article are included in the article's Creative Commons licence, unless indicated otherwise in a credit line to the material. If material is not included in the article's Creative Commons licence and your intended use is not permitted by statutory regulation or exceeds the permitted use, you will need to obtain permission directly from the copyright holder. To view a copy of this licence, visit http://creativecommons.org/licenses/by/4.0/.

\section{References}

1. Li D, Ambrogio L, Shimamura T et al (2008) BIBW2992, an irreversible EGFR/HER2 inhibitor highly effective in preclinical lung cancer models. Oncogene 27(34):4702-4711. https://doi.org/ 10.1038/onc.2008.109

2. Solca F, Dahl G, Zoephel A et al (2012) Target binding properties and cellular activity of afatinib (BIBW 2992), an irreversible ErbB family blocker. J Pharmacol Exp Ther 343(2):342-350. https://doi. org/10.1124/jpet.112.197756

3. Yang JC, Sequist LV, Geater SL et al (2015) Clinical activity of afatinib in patients with advanced non-small-cell lung cancer harbouring uncommon EGFR mutations: a combined post-hoc analysis of LUX-Lung 2, LUX-Lung 3, and LUX-Lung 6. Lancet Oncol 16(7):830-838. https://doi.org/10.1016/S1470-2045(15) 00026-1

4. Cappuzzo F, Soo R, Hochmair M et al (2018) Global named patient use program of afatinib in advanced non-small-cell lung carcinoma patients who progressed following prior therapies. Future Oncol 14(15):1477-1486. https://doi.org/10.2217/ fon-2017-0666

5. Choi MK, Ahn JS, Kim YC et al (2018) Afatinib in heavily pretreated advanced NSCLC patients who progressed following prior gefitinib or erlotinib: compassionate use program in Korea. Lung Cancer 119:36-41. https://doi.org/10.1016/j.lungcan.2018.02.020

6. Heigener DF, Schumann C, Sebastian M et al (2015) Afatinib in non-small cell lung cancer harboring uncommon EGFR mutations pretreated with reversible EGFR inhibitors. Oncologist 20(10):1167-1174. https://doi.org/10.1634/theoncologist. 2015-0073

7. Khan F, Ottensmeier C, Popat S et al (2014) Afatinib use in nonsmall cell lung cancer previously sensitive to epidermal growth factor receptor inhibitors: the United Kingdom Named Patient Programme. Eur J Cancer 50(10):1717-1721. https://doi.org/10. 1016/j.ejca.2014.03.001

8. Schuler M, Fischer JR, Grohe C et al (2014) Experience with afatinib in patients with non-small cell lung cancer progressing after clinical benefit from gefitinib and erlotinib. Oncologist 19(10):1100-1109. https://doi.org/10.1634/theoncologist. 2014-0103

9. Peters S, Curioni-Fontecedro A, Nechushtan H et al (2018) Activity of afatinib in heavily pretreated patients with ERBB2 mutation-positive advanced NSCLC: findings from a global named patient use program. J Thorac Oncol 13(12):1897-1905. https:// doi.org/10.1016/j.jtho.2018.07.093

10. Graham RP, Treece AL, Lindeman NI et al (2018) Worldwide frequency of commonly detected EGFR mutations. Arch Pathol Lab Med 142(2):163-167. https://doi.org/10.5858/arpa.2016-0579-CP

11. Miller VA, Hirsh V, Cadranel J et al (2012) Afatinib versus placebo for patients with advanced, metastatic non-small-cell lung cancer after failure of erlotinib, gefitinib, or both, and one or two 
lines of chemotherapy (LUX-Lung 1): a phase $2 b / 3$ randomised trial. Lancet Oncol 13(5):528-538. https://doi.org/10.1016/S14702045(12)70087-6

12. Chang, G-C et al. Afatinib named patient use program in advanced NSCLC with progression on prior therapy: experience from Asian centers. IASLC Asia Conference on Lung Cancer. Guangzhou, China. November 8-10, 2018.

13. De Pas T, Toffalorio F, Manzotti M et al (2011) Activity of epidermal growth factor receptor-tyrosine kinase inhibitors in patients with non-small cell lung cancer harboring rare epidermal growth factor receptor mutations. J Thorac Oncol 6(11):1895-1901. https://doi.org/10.1097/JTO.0b013e318227e8c6

14. Wu JY, Yu CJ, Chang YC et al (2011) Effectiveness of tyrosine kinase inhibitors on "uncommon" epidermal growth factor receptor mutations of unknown clinical significance in non-small cell lung cancer. Clin Cancer Res 17(11):3812-3821. https://doi.org/ 10.1158/1078-0432.CCR-10-3408

15. Kosaka T, Tanizaki J, Paranal RM et al (2017) Response heterogeneity of EGFR and HER2 Exon 20 insertions to covalent EGFR and HER2 inhibitors. Cancer Res 77(10):2712-2721. https://doi. org/10.1158/0008-5472.CAN-16-3404

16. Oxnard GR, Lo PC, Nishino M et al (2013) Natural history and molecular characteristics of lung cancers harboring EGFR exon 20 insertions. J Thorac Oncol 8(2):179-184. https://doi.org/10. 1097/JTO.0b013e3182779d18

17. Naidoo J, Sima CS, Rodriguez K et al (2015) Epidermal growth factor receptor exon 20 insertions in advanced lung adenocarcinomas: clinical outcomes and response to erlotinib. Cancer 121(18):3212-3220. https://doi.org/10.1002/cncr.29493

18. Yasuda H, Park E, Yun CH et al (2013) Structural, biochemical, and clinical characterization of epidermal growth factor receptor (EGFR) exon 20 insertion mutations in lung cancer. Sci Transl Med 5 (216):216ra177. doi:https://doi.org/10.1126/scitranslmed. 3007205

19. Lin YT, Liu YN, Wu SG et al (2017) Epidermal growth factor receptor tyrosine kinase inhibitor-sensitive exon 19 insertion and exon 20 insertion in patients with advanced non-small-cell lung cancer. Clin Lung Cancer 18 (3):324-332 e321. doi:https://doi. org/10.1016/j.cllc.2016.12.014

20. Chan RT (2018) Afatinib for an EGFR exon 20 insertion mutation: a case report of progressive stage IV metastatic lung adenocarcinoma with 54 months' survival. Asia Pac J Clin Oncol 14(Suppl 1):7-9. https://doi.org/10.1111/ajco.12853

21. Liu Z, Wu L, Cao J et al (2018) Clinical characterization of ERBB2 exon 20 insertions and heterogeneity of outcomes responding to afatinib in Chinese lung cancer patients. Onco Targets Ther 23(11):7323-7331. https://doi.org/10.2147/OTT.S1733 91

22. Shigematsu H, Takahashi T, Nomura M et al (2005) Somatic mutations of the HER2 kinase domain in lung adenocarcinomas. Cancer Res 65(5):1642-1646. https://doi.org/10.1158/0008-5472. CAN-04-4235

23. Arcila ME, Chaft JE, Nafa K et al (2012) Prevalence, clinicopathologic associations, and molecular spectrum of ERBB2 (HER2) tyrosine kinase mutations in lung adenocarcinomas. Clin Cancer Res 18(18):4910-4918. https://doi.org/10.1158/10780432.CCR-12-0912

24. Buttitta F, Barassi F, Fresu G et al (2006) Mutational analysis of the HER2 gene in lung tumors from Caucasian patients: mutations are mainly present in adenocarcinomas with bronchioloalveolar features. Int J Cancer 119(11):2586-2591. https://doi.org/10.1002/ ijc. 22143

25. Stephens P, Hunter C, Bignell G et al (2004) Lung cancer: intragenic ERBB2 kinase mutations in tumours. Nature 431(7008):525-526. https://doi.org/10.1038/431525b

26. Yang JC, Ahn MJ, Kim DW et al (2017) Osimertinib in pretreated T790M-positive advanced non-small-cell lung cancer: AURA study phase II extension component. J Clin Oncol 35(12):12881296. https://doi.org/10.1200/JCO.2016.70.3223

27. Ahn M, Cho J, Sun J et al (2018) An open-label, multicenter, phase II single arm trial of osimertinib in non-small cell lung cancer patients with uncommon EGFR mutation (KCSG-LU15-09). J Clin Oncol 36(Suppl 15):9050. https://doi.org/10.1200/JCO.2018. 36.15_suppl.9050

Publisher's Note Springer Nature remains neutral with regard to jurisdictional claims in published maps and institutional affiliations.

\section{Authors and Affiliations}

\section{Gee-Chen Chang ${ }^{1,2,3} \cdot$ David Chi-Leung Lam ${ }^{4} \cdot$ Chun-Ming Tsai ${ }^{5} \cdot$ Yuh-Min Chen $^{6} \cdot$ Jin-Yuan Shih $^{7}$. Shyam Aggarwal ${ }^{8}$. Shuhang Wang ${ }^{9}$. Sang-We Kim ${ }^{10}$ - Young-Chul Kim ${ }^{11} \cdot$ Ibrahim Wahid $^{12} \cdot$ Rubi Li $^{13} \cdot$ Darren Wan-Teck Lim ${ }^{14}$. Virote Sriuranpong ${ }^{15} \cdot$ Raymond Tsz-Tong Chan $^{16} \cdot$ Robert M. Lorence $^{17} \cdot$ Philippe Carriere $^{17} \cdot$ Christina Raabe $^{18}$. Agnieszka Cseh ${ }^{19} \cdot$ Keunchil Park ${ }^{20}$}

1 Division of Chest Medicine, Department of Internal Medicine, Taichung Veterans General Hospital, No. 1650, Section 4, Taiwan Boulevard, Xitun District, Taichung, Taiwan

2 Division of Pulmonary Medicine, Department of Internal Medicine, Chung Shan Medical University Hospital, Taichung, Taiwan

3 Institute of Medicine and School of Medicine, Chung Shan Medical University, Taichung, Taiwan

4 Queen Mary Hospital, The University of Hong Kong, Hong Kong, China

5 Taipei Veterans General Hospital, Taipei, Taiwan
6 Department of Chest Medicine, Taipei Veterans General Hospital, and School of Medicine, National Yang-Ming Medical University, Taipei, Taiwan

7 National Taiwan University Hospital, Taipei, Taiwan

8 Sir Ganga Ram Hospital Rajinder Nagar, New Delhi, India

9 Beijing Cancer Hospital, Beijing, China

10 Asan Medical Center, University of Ulsan College of Medicine, Seoul, Republic of Korea

11 Chonnam National University, Hwasun Hospital, Jeonnam, Republic of Korea

12 Beacon International Specialist Centre, Selangor, Malaysia 
13 St Luke's Medical Center, Quezon City, Philippines

14 National Cancer Centre, Singapore, Singapore

15 Chulalongkorn University and the King Chulalongkorn Memorial Hospital, Pathumwan, Bangkok, Thailand

16 Hong Kong Pacific Centre, Kowloon, Hong Kong, China

17 Boehringer Ingelheim Pharmaceuticals, Inc., Ridgefield, CT, USA
18 Boehringer Ingelheim International $\mathrm{GmbH}$, Ingelheim Am Rhein, Germany

19 Boehringer Ingelheim RCV GmBH \& Co. KG, Vienna, Austria

20 Samsung Medical Center, Sungkyunkwan University School of Medicine, Seoul, Republic of Korea 